\title{
"Hoje somos nós os escultores!" AgenCIALIDADe e ARTE PúbliCA PARTICIPADA em Almada
}

\author{
Maria Assunção Gato ${ }^{1}$, Filipa Ramalhete ${ }^{2}$ e Sérgio Vicente ${ }^{3}$
}

Neste artigo propóe-se uma reflexão sobre um projecto de arte pública participada, com base numa leitura critica das teorias de Gell em torno da arte en quanto sistema de aç̧ão e da agencialidade dos objectos artísticos. A característica inovadora deste projecto assenta num processo de concepção de arte pública desenvolvido através da participação de um grupo de residentes no Monte de Caparica (concelho de Almada, Portugal), que também integram a comunidade a quem é dirigida a obra artística. Do enquadramento desta experiência com algumas propostas de Gell sublinha-se que o papel activo que os objectos artisticos desempenham no sistema de acção social é indissociável das propriedades simbólicas, estéticas, representativas e comunicacionais que os integram. Também se preconiza um reforço da capacidade agencial dos objectos artísticos através de formas participadas de produção semelhantes à descrita aqui. Esta experiência resulta de uma perspectiva antropológica sobre o terreno, orientada para a construção de uma metodologia de participação aplicada à concepção do objecto artístico.

Palavras-chave: agencialidade, arte pública, participação, multiculturalidade.

\section{INTRODUÇÃo}

Toda a acção humana, na medida em que é social, acontece sempre num contexto que envolve regras, objectivos, intenções, recursos e competências ou seja, elementos constituintes

1 DINÂMIA'CET-IUL (Centro de Estudos sobre a Mudança Socioeconómica e o Território - Instituto Universitário de Lisboa).

2 e-GEO/FCSH-UNL (Centro de Estudos de Geografia e Planeamento Regional - Faculdade de Ciências Sociais e Humanas da Universidade Nova de Lisboa), CEACT-UAL (Centro de Estudos de Arquitectura, Cidade e Território - Universidade Autónoma de Lisboa).

3 CIEBA.ESC/FBAUL (Centro de Investigação e Estudos em Belas Artes. Escultura - Faculdade de Belas Artes da Universidade de Lisboa). 
de qualquer realidade social, que tanto limitam as acções dos indivíduos como os motivam a procurar novas estratégias para lidarem com essas limitações. Assim, todo o processo de acção corresponde à produção de algo novo, ao mesmo tempo que toda a acção apenas existe na continuidade com o passado, que fornece os meios para que ela se inicie (Giddens, 2000).

Dando seguimento a esta linha de raciocínio, a produção artística pode ser considerada como um elemento privilegiado de acção, na medida em que não só reflecte uma determinada realidade social situada num tempo e num espaço, como é também uma manifestação cultural produzida a partir dessa mesma realidade e cujos propósitos, por mais variados que sejam, acrescentam sempre algo ao património social, cultural e identitário do grupo.

É com base nestas premissas que se justifica o enquadramento do projecto de arte pública participada que se desenvolveu junto da comunidade residente no Monte de Caparica ${ }^{4}$ com o enriquecedor contributo que Gell (1998) deixou à Antropologia da Arte, através das suas propostas teóricas sobre as capacidades agenciadoras dos indivíduos e das coisas que eles produzem.

Ao focalizar a Arte sobre um sistema de acção baseado em contextos sociais de produção, circulação e recepção das obras artísticas, Gell introduziu alguma inovação no entendimento da produção artística. Mais concretamente assentou a sua concepção de arte num sistema relacional, em que o sentido dos objectos resulta das relações sociais que se geram à sua volta. Desta forma, os objectos de arte são entendidos por Gell como "índices" de agencialidade social ou seja, entidades materiais construídas por "agentes" sociais, com o intuito de provocar acções ou reaç̧ões em "pacientes" (ou destinatários). Dito de outro modo, os objectos de arte são testemunhos materiais inseridos em contextos sociais específicos e produzidos com base nas relações sociais existentes entre quem desencadeia uma acção e os destinatários ou os visados pela mesma.

Apesar da discussão teórica em torno da expressão social dos objectos já não ser novidade em Antropologia (cf. Appadurai 1986), ela beneficiou bastante com o papel activo e interventivo que Gell imputou aos objectos artísticos, atribuindo-lhes uma agencialidade equiparável aos próprios indivíduos. Tal como as acções, também os objectos por eles produzidos possuem alguma capacidade de agir e transformar o mundo, ao invés de se limitarem a codificá-lo através de proposições simbólicas ou de formalizações estéticas. Contudo, este autor também considerou que os objectos de arte não correspondem a um produto acabado nem podem ser agentes autosuficientes ou "agentes primários". Neste sentido, os objectos de arte agem enquanto extensões ou "índices" da agencialidade de alguém, cabendo-lhes a designação de "agentes secundários".

É nessa qualidade que Gell procura justificar o papel activo dos objectos artísticos no sistema de acção social, no qual desencadeiam reacções, comportamentos e outras iniciativas performativas. Porém, a clarificação quanto ao tipo de agencialidade conferida aos objectos não se faz acompanhar de uma exposição mais precisa quanto à sua forma de actuar enquanto extensões da agencialidade de alguém. Por outras palavras, ao admitir os objectos de arte como um prolongamento de intenções ou ideias que são passadas entre "agentes" e "pacientes" com

4 O Monte de Caparica é uma vila pertencente ao concelho de Almada, na margem Sul do rio Tejo. É também sede da freguesia de Caparica, uma das mais populosas do concelho, onde ao longo das últimas décadas se foram desenvolvendo programas de habitação social que levaram à concentração de grupos sociais de estratos económicos baixos e com origens étnicas muito diversificadas. 
objectivos de provocar reacções, Gell acaba por contornar a questão relativa à forma como essas ideias são passadas e recebidas através dos objectos. Este facto prende-se directamente com a desvalorização que Gell dirige às propriedades estéticas dos objectos e às suas capacidades de comunicar através de códigos simbólicos, em benefício de uma teoria que procura autonomizar o objecto relativamente a esses códigos semióticos e linguísticos.

É um facto que a possibilidade de percepcionar as teias de relações que se estabelecem entre "quem faz", "aquilo que é feito" e "quem recebe" constitui, sem dúvida, uma vantagem importante à consolidação de um corpo teórico para a Antropologia da Arte, assim como no fortalecimento de outras áreas de estudo dentro da Antropologia relacionadas com o consumo e com a cultura material (e.g. Appadurai 1986; Baudrillard 1973; Miller 1987; Lury 1997). Neste sentido Gell tornou-se uma referência importante, contribuindo para um entendimento mais holístico e relacional dos indivíduos com os seus objectos e, consequentemente, para a compreensão dos comportamentos gerados nesta relação.

Contudo, as suas formulações teóricas também provocaram algumas ondas de crítica, que se focaram sobretudo no seu propósito de desviar os objectos de arte das habituais avaliações estéticas e simbólicas (Thomas, 2001). Nestas ondas de crítica também Layton (2003) considera que Gell acabou por minimizar algumas componentes que são intrínsecas à arte, muito por via do contexto de comunicação simbólica em que é criada. Ao mesmo tempo que Layton reconhece o mérito da concepção relacional que Gell constroi em torno da agencialidade - de pessoas e objectos - também critica a desvalorização que ele dedica aos sentidos e significados dos objectos, enquanto mensagens partilhadas entre emissores e receptores. $\mathrm{Na}$ sua opinião, não só a arte implica, por si só, a capacidade de influenciar as mentes, como a própria agencialidade que Gell atribui aos objectos implica a necessidade de leitura e de entendimento dos mesmos no seu contexto relacional, o qual não está isento das respectivas convenções culturais.

A propósito destas convenções culturais refira-se também Geertz (1993), para quem a acção social só existe porque tem um sentido orientado para algo ou para alguém. Nesta perspectiva Geertz entende a Cultura enquanto "texto", cuja leitura pressupõe a partilha de um campo semântico, em que intérprete e interpretado são colocados ao mesmo nível, influenciandose mutuamente em função do sentido implícito nas suas aç̧ões. Ainda que Geertz não se refira especificamente à arte ou aos seus objectos, dentro do vasto campo que é a cultura ele também particulariza os objectos pelas características que os diferenciam dos demais. Destas características farão parte o "sentido" e as relações sociais que os objectos geram à sua volta.

Esta breve referência a Geertz permite reforçar algumas das críticas colocadas a Gell e, sobretudo sublinhar que os objectos de arte, enquanto extensões da agencialidade social, não são alheios ao sistema cultural que os envolve e que inclui codificações de natureza simbólica sobre a realidade envolvente. Neste contexto se compreende a capacidade das sociedades se interpretarem e representarem através dos seus espaços, quer físicos, quer de memória (Connerton, 1993), bem como a capacidade das identidades espaciais, culturais e das pertenças sociais se reflectirem e comunicarem através de objectos, nomeadamente, objectos de arte.

Em suma, não obstante algumas fragilidades teóricas relacionadas com a demarcação intencional de Gell face aos modelos de análise de inspiração estruturalista e semiológica, importa sublinhar o mérito da sua teoria antropológica da arte, quer na agencialidade que confere aos objectos, quer na dimensão social e relacional em que os situa. No essencial, esta 
breve exposição sobre a conceptualização teórica de Gell em torno do objecto artístico serve o propósito de estabelecer pontes de discussão com o projecto artístico que se apresentará em seguida. Através dele pretende-se ilustrar a dimensão relacional dos objectos de arte com o território, com o contexto social e as circunstâncias em que foram produzidos, defendendo que as leituras simbólicas não inviabilizam a sua agencialidade. Em seguida sugere-se o papel complementar que processos participados de arte pública podem desempenhar junto da agencialidade de objectos artísticos.

\section{Um Projecto de arte pública participada para o Monte de Caparica}

O projecto de arte pública que está no centro da discussão teórica enunciada atrás surgiu de uma proposta feita à Câmara Municipal de Almada pelo Centro de Investigação e Estudos em Belas Artes (CIEBA) da Faculdade de Belas Artes de Lisboa, em resposta à intenção municipal de lançar, durante o mandato autárquico, as bases para a concepção e instalação de um monumento à multiculturalidade no concelho, destinado ao novo parque urbano do Monte de Caparica.

Tal proposta consistiu no desenvolvimento e implementação de um projecto de arte pública, que fosse concebido com a comunidade residente na área envolvente do parque urbano, contrariando assim os procedimentos contratuais ${ }^{5}$ usados pelo município de Almada em matéria de arte pública existente no seu território. Desta forma não só se dava a oportunidade à comunidade de participar numa acção concreta dirigida ao seu território, como se potenciava um maior diálogo e entrosamento social no seio de uma comunidade bastante complexa e culturalmente diversificada.

Com efeito, foi um grupo composto por uma média de quarenta residentes na área respondendo a um convite que se estendeu a toda a comunidade residente e que foi sendo divulgado em diversos locais de proximidade através de fontes diversas ao longo de todo o período de desenvolvimento do projecto, como se exemplifica na foto 1 - quem idealizou, discutiu e projectou várias propostas artísticas para o seu parque urbano, ao longo das sete sessões de trabalho (ou workshops) organizadas por uma equipa interdisciplinar ${ }^{6}$ coordenada pelo escultor responsável ${ }^{7}$ por este projecto.

Sobre o número médio de participantes envolvidos nas várias sessões de trabalho importará referir que, apesar de não cumprir com uma representatividade estatística face ao universo dos residentes no Monte de Caparica, este revelou-se adequado ao tipo de metodologias utilizadas e que serão explicadas mais à frente. Paralelamente, o prévio reconhecimento do território e das comunidades em presença também apontava para um nível de participação que se destacaria

5 Até à implementação deste projecto todas as obras de arte pública existentes no Concelho de Almada surgiram através do processo tradicional de encomenda pública (concurso público, subscrição popular ou encomenda directa).

6 A Equipa foi constituída por dois escultores, duas antropólogas, um psicólogo social e três alunos do curso de escultura da Faculdade de Belas Artes de Lisboa que também prestaram apoio à realização das propostas e maquetagem. Teve como parceiros o Centro de Estudos de Arquitectura, Cidade e Território da Universidade Autónoma de Lisboa e o Clube Recreativo União Raposense.

7 Escultor Sérgio Vicente, que no ano de 1995, em resultado de um concurso público já realizara um monumento em Almada, "Monumento À Vida”, implantado noutra freguesia do Concelho. 
menos pela quantidade de elementos em benefício da diversidade de referências culturais dos mesmos e da riqueza das suas experiências de vida. Com efeito, os resultados obtidos nas diferentes sessões permitiram verificar a importância destes elementos na prática artística informal revelada por este grupo.

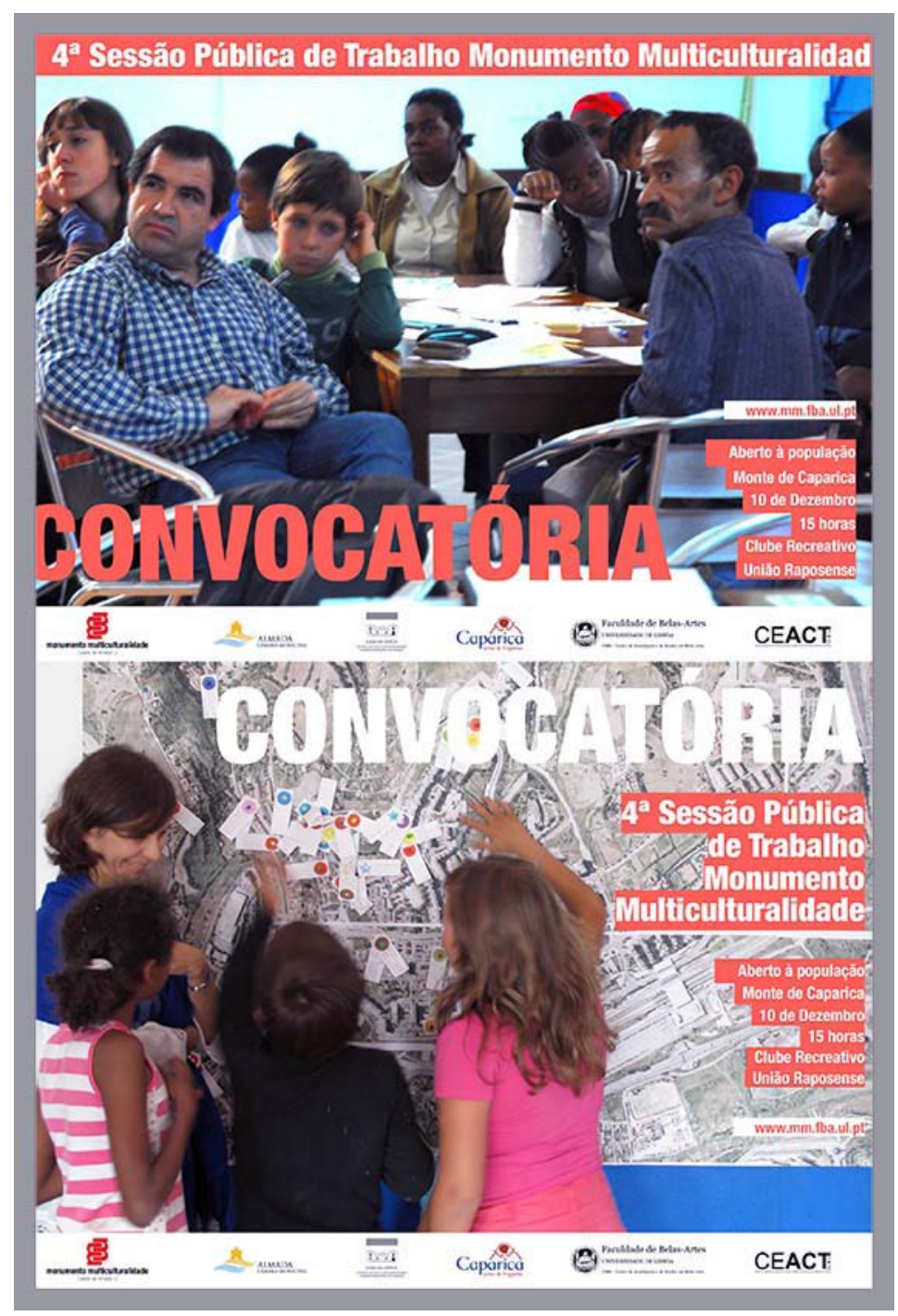

Foto 1 - Exemplos dos modos de divulgação das sessões públicas de trabalho.

\section{O TERRITÓRIO MULTICULTURAL}

Foi precisamente atendendo à diversidade sociocultural que caracteriza este território que o projecto de arte pública participada recebe do município de Almada a designação oficial de "Monumento à Multiculturalidade". Este "monumento" teve como destino o novo parque urbano que integra o Centro Cívico de Caparica, onde ao parque se junta uma biblioteca, um complexo de piscinas e uma nova sede de um clube recreativo local. No conjunto são equipamentos de apoio a uma população carenciada, que surgiram no âmbito do plano de 
recuperação e reconversão urbana "Almada Poente", para uma área delimitada dentro do antigo Plano Integrado de Almada (PIA). O PIA foi criado pelo extinto Fundo de Fomento da Habitação, entre o final da década de 1960 e início de 1970, com objectivos de ali "fazer cidade" através da construção de um novo pólo urbano, com alguma autonomia, diversidade social e oferecendo mais qualidade de vida a populações carenciadas do concelho de Almada.

Desde o início da implementação deste programa habitacional, em 1971, passando pelos conturbados anos da pós-revolução de 1974, até à criação do Instituto de Gestão e Alienação do Património Habitacional do Estado (IGAPHE) em 1987, a zona de intervenção do PIA foi-se tornando num local de grande concentração de grupos sociais de estratos económicos baixos e de origens étnicas muito diversificadas.

A primeira ocupação, que data de 1979, foi feita por grupos de forte carácter comunitário provenientes de Almada, da região de Lisboa e retornados das ex-colónias portuguesas em África. A partir de meados dos anos de 1980 a ocupação tornou-se mais diversificada e instalaram-se na zona outras etnias migrantes e comunidades ciganas.

Actualmente, a área urbana onde se localiza o PIA continua a reflectir algumas dificuldades de integração e coesão ao nível social e urbano. As características orográficas, a forte predominância da função residencial e o facto de a mesma estar maioritariamente associada a programas de apoio social contribuiu para que este território fosse projectando no exterior uma imagem estigmatizada, acompanhada de alguns sintomas de segregação social.

A degradação observável nos diversos espaços públicos que articulam os conjuntos habitacionais não só reproduz os problemas sociais, económicos e culturais de quem neles habita, como também contribui bastante para que estes lugares continuem a apresentar algumas dificuldades de integração e coesão ao nível social e urbano (Costa, 2005, 2006; Almada, 2008).

Se, por um lado, a diversidade - étnica, etária e até mesmo religiosa - funciona como um dos traços sociais mais relevantes deste território e, simultaneamente, catalisador de inúmeras tensões internas, por outro, a partilha de um mesmo espaço de vida quotidiana constrange os residentes a participar da mesma imagem desvalorizada que se projecta no exterior.

É neste contexto que surge o Centro Cívico de Caparica e o respectivo parque urbano, no âmbito do qual houve a possibilidade de projectar arte pública através de um processo de participação que, como se referiu atrás, foi experimental em Almada, não se conhecendo outras experiências semelhantes em Portugal.

\section{UMA METODOLOGIA POSSÍVEL}

Tendo em conta as características socioculturais da população-alvo, os objectivos de participação comunitária que se pretendiam alcançar através deste projecto de arte pública e o

8 Em 2004 foi assinado um protocolo entre a autarquia e o estado central, o Instituto da Habitação e Reabilitação Urbana (IHRU) para o Plano Estratégico de Almada Poente, um Programa Integrado de Regeneração Urbana com base nos apoios financeiros do QREN-Polis XXI, com o objectivo de implementar a recuperação e reconversão urbana daquela zona da cidade. 
desconhecimento de experiências semelhantes em Portugal, houve a necessidade de proceder à elaboração de uma metodologia que permitisse orientar este processo de participação dirigido à arte pública.

Em traços gerais, a metodologia desenvolvida visava a criação de uma dinâmica capaz de integrar as representações sociais e espaciais da população local no próprio "monumento", desde a sua conceptualização até à construção. Para fomentar essa dinâmica aplicaram-se algumas ideias inspiradas em modelos de promoção de participação pública utilizados em contextos de planeamento e ordenamento do território ${ }^{9}$, nomeadamente sessões de trabalho - ou workshops geralmente dinamizadas por equipas interdisciplinares e assentes em desafios propostos a grupos aleatoriamente constituídos e com vista à concretização de uma aç̧ão, concreta ou hipotética.

A experiência prévia de alguns elementos da equipa em processos de participação pública envolvendo o associativismo de Almada foi também determinante para a opção por este tipo de metodologia. Com efeito, tanto o conhecimento prévio deste território e do tecido associativo local, como a experiência de aplicação de metodologias semelhantes em sessões públicas de participação sobre ordenamento territorial davam algumas garantias de sucesso relativamente à mobilização de parte da população para o desenvolvimento deste projecto.

Igualmente relevantes foram alguns casos de estudo de arte pública participada desenvolvidos em Barcelona (Aguilera, 2004; Águas, 2012; Remesar e Vidal, 2003), não só por constituírem uma referência importante para os procedimentos metodológicos desenvolvidos neste projecto e comprovarem a importância dos processos participativos para potenciar relações de pertença face ao espaço intervencionado, como também por permitirem colmatar o desconhecimento de experiências semelhantes em Portugal.

Um exemplo é o trabalho que tem sido desenvolvido pelo CRPolis (Centro de Recerca Polis) da Universidade de Barcelona, usando as práticas sociais como ferramenta para a tomada de decisões sobre o desenho do espaço público. Através dos chamados talleres de Projectes - que resultam do apuramento operativo de modelos participativos anteriores como os NIP (Núcleos de Intervenção Participativa) - esse trabalho exemplifica a forma como se pode desenvolver projectos de arte pública a partir da interpretação de metodologias da participação cidadã já experimentadas noutras áreas de conhecimento.

Em Barcelona, a ideia de "oficina de projecto" é enriquecida pela opção transdisciplinar de introduzir outras áreas disciplinares que têm o desenho como propósito. O trabalho com os cidadãos é desenvolvido de forma a fornecer-lhes ferramentas e métodos para o diagnóstico, crítica e discussão de propostas que incidam sobre o seu espaço vivencial.

Remesar (2005) acrescenta que a metodologia de projecto desenvolvida nestas "oficinas" assenta em duas ideias complementares: o "desígnio" traduzido na consciência e na vontade de transformar a realidade e o desenho enquanto conjunto de procedimentos que permitem a materialização do projecto. No contexto do seu projecto sobre a tomada de decisão sobre os usos sociais no último troço do rio Besòs, em Barcelona, o autor propõe o desenvolvimento de uma

9 Foram tidos como referências os processos de participação desenvolvidos pelo Departamento de Ambiente da Universidade Nova de Lisboa, mais concretamente, pela equipa do Civitas21 (cf. http://www.civitas21.pt/ homepage) em planos municipais de ambiente e no processo de elaboração dos estudos para o Plano de Pormenor da Cova da Moura, na Amadora. 
estratégia participativa de oficinas de projecto e intervenção social, defendendo a introdução da "metodologia do projecto" resgatada de disciplinas como a arquitectura, o design ou engenharia. Esta proposta vai no sentido de permitir que a participação avance para além das habituais metodologias, muito limitadas à detecção de problemas e consulta das possíveis soluções a aplicar.

De volta ao Monte de Caparica, todas estas reflexões serviram de inspiração a uma metodologia que procurou articular a reflexão de um grupo de pessoas sobre o seu território, com a criação e experimentação artística. Do conjunto das sessões resultou o envolvimento de todos os intervenientes - comunidade e equipa - numa dinâmica criativa desenvolvida em torno de várias propostas para um "monumento", que representará algo mais do que uma ideia de "multiculturalidade" para quem as concebeu. Em paralelo com o "monumento" também se concretizou uma forma de arte pública participada, entendendo-se que esta designação pressupõe o controlo estético dos cidadãos sobre o seu espaço vivencial (Remesar, 2005), através de uma acção partilhada sobre o destino que lhe é dado.

\section{A EXPERIÊNCIA ARTÍSTICA}

O "monumento à multiculturalidade" foi desenvolvido ao longo de um ano, através de sete sessões públicas de trabalho realizadas na sede do Clube Recreativo União Raposense, um clube recreativo e desportivo local situado no Parque Urbano que o vai acolher. As sessões estiveram sempre abertas à participação de qualquer membro da comunidade, independentemente da faixa etária, como é perceptível na foto 2. Para tal eram previamente anunciadas, de diversas formas e em diversos locais públicos.

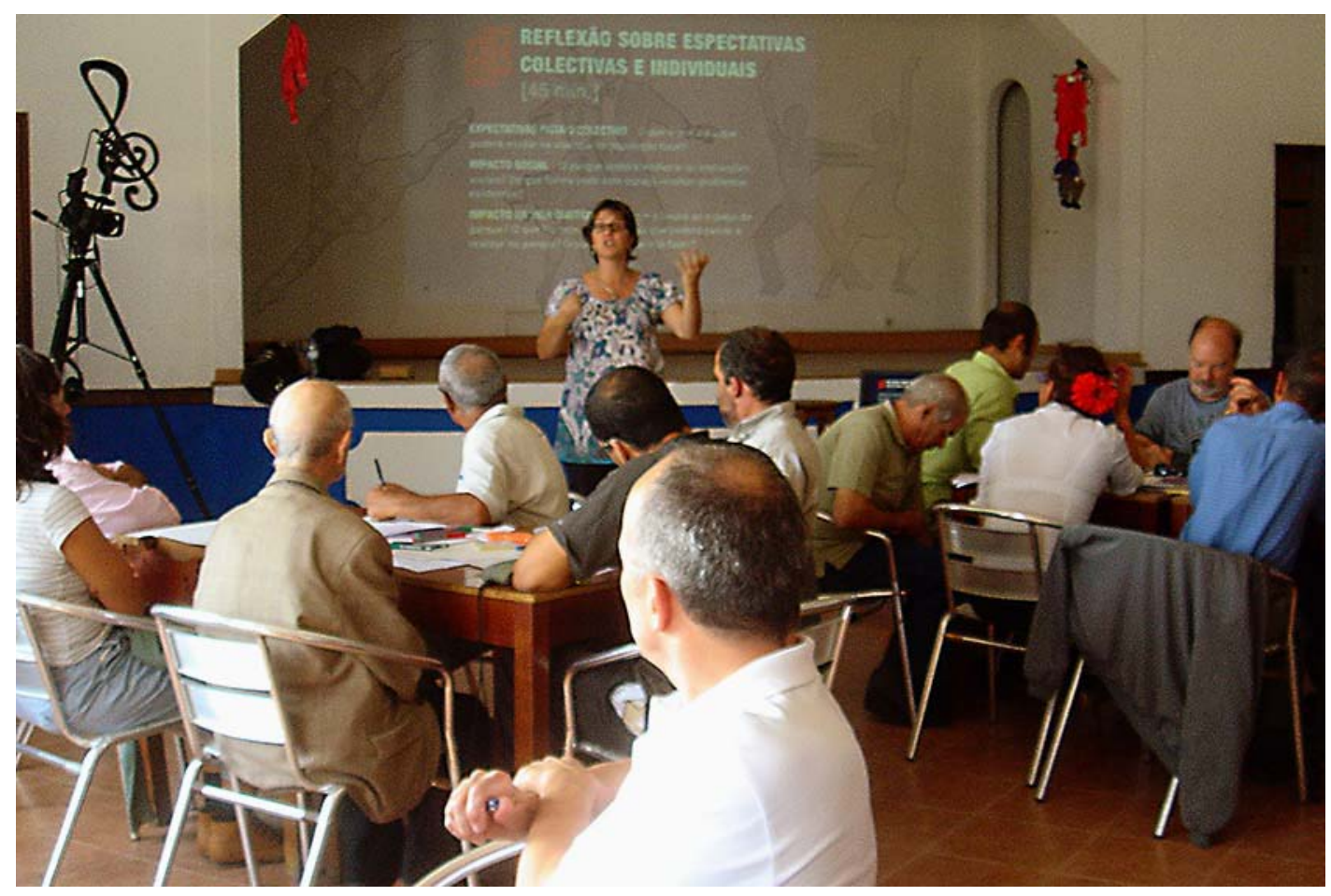

Foto 2 - Panorama da $1^{\text {a }}$ sessão pública de trabalho. 
No arranque deste projecto foi criado um sítio na internet ${ }^{10}$ destinado a colocar fotografias e toda a informação relativa às sessões de trabalho, à medida que as mesmas iam acontecendo. Também se procedeu à filmagem das sessões com vista à produção de um futuro documentário.

Com a ajuda complementar destes suportes convocou-se a participação dos membros da comunidade para a realização de duas etapas de trabalho. A primeira etapa visava a autoprodução de percepções espaciais, memórias e discursos sobre experiências de partilha de um território comum. Para tal e ao longo de três sessões ${ }^{11}$ os participantes foram desafiados a reflectir e a responder a questões em torno da caracterização do seu território, incluindo áreas mais valorizadas e expectativas sobre o espaço e vivências sociais. Pretendia-se assim que a comunidade fosse gerando algumas reflexões que ajudassem a representar as especificidades do seu território.

Como é visível na foto 2 , procedeu-se à divisão dos participantes por vários grupos de trabalho, cuja constituição foi variando de sessão para sessão de forma a possibilitar maior diversidade nas interacções sociais e no debate de ideias.

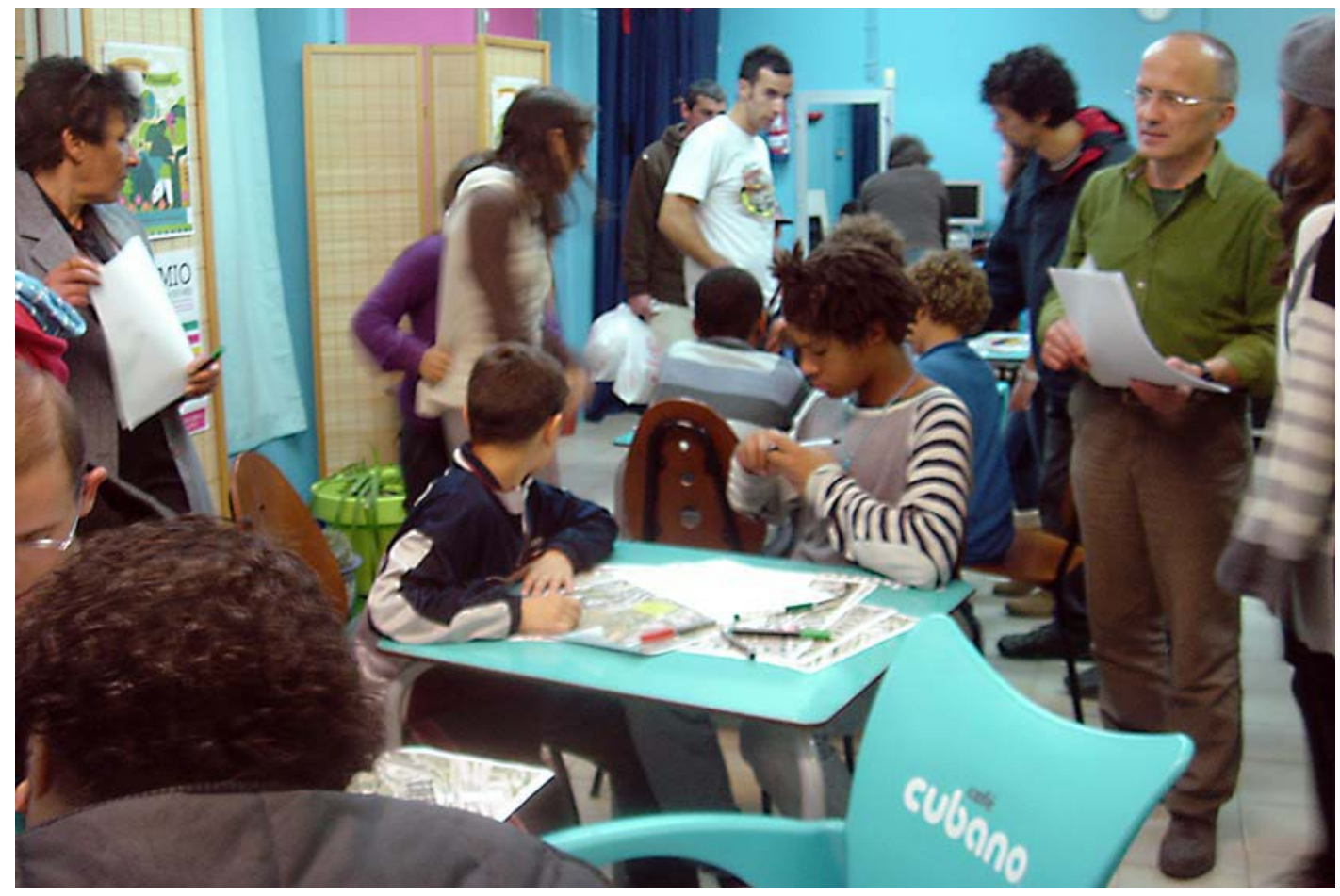

Foto 3 - Panorama da $2^{a}$ sessão pública de trabalho com crianças e jovens.

No final das sessões os representantes de cada grupo apresentavam em plenário os resultados a que tinham chegado e, uma vez sintetizados pela equipa, esses resultados constituíam-se como base de partida para a sessão de trabalho seguinte. Importará ainda referir que a segunda sessão foi exclusivamente dirigida à população residente mais jovem, como se ilustra na foto 3 . $\mathrm{O}$ objectivo foi dar voz a um grupo etário bastante representativo desta população ${ }^{12}$ e confrontar as suas perspectivas e expectativas socioespaciais com os restantes grupos etários participantes.

10 Http://www.mm.fba.ul.pt/monumento_multiculturalidade/home.html

11 Realizadas respectivamente em 22/10/2011, 23/11/2011 e 26/11/2011.

12 De acordo com os Censos de 2011 a percentagem de jovens (entre os 0 e os 19 anos) na freguesia de 
Desta primeira etapa resultou, num primeiro momento, a seguinte listagem de ideiassíntese sobre o território: a diversidade social (etária, étnica) da comunidade; o universo intercultural presente nas escolas; a juventude e os reflexos da sua presença e acção (nem sempre positiva) no espaço público; o ambiente de insegurança sentido pela comunidade; a ausência de lugares de partilha e vivência colectiva; o cruzamento de valores envolvendo o património material, memórias espaciais e diversidade sociocultural.

A estas ideias-síntese juntaram-se outras suscitadas pelos jovens, como "graffiti", "vandalismo", "amarelo", "branco" e "azul'. Estas ideias não só reflectem realidades mais próximas deste grupo etário, como são identificadoras do território por onde ele mais circula, na medida em que as cores referidas remetem para a designação atribuída aos diferentes bairros que compõem este território. Num segundo momento os participantes foram desafiados a converter todas estas ideias-síntese em três palavras-chave (por grupo) que, no conjunto, traduzissem a sua realidade espacial e social. A partir daqui e organizando as três palavras-chave numa sequência narrativa lógica, os representantes dos grupos apresentaram as suas conclusões a todos os presentes ${ }^{13}$.

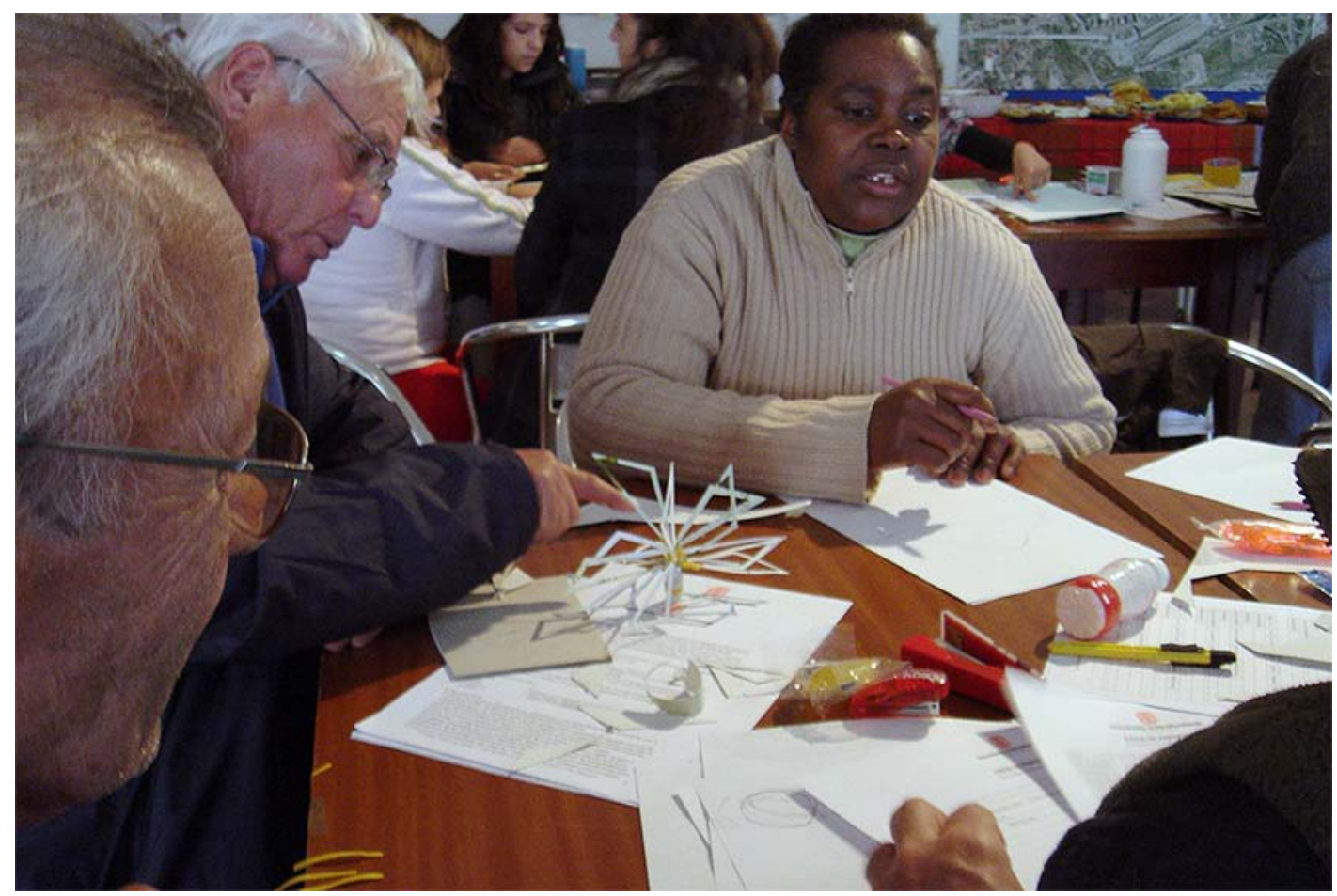

Foto 4 - Início do desenvolvimento das maquetas por parte dos participantes na sessão de trabalho.

Caparica é de 27,6\%, sendo superior à percentagem do concelho de Almada (24,6\%) e à do país (25,6\%).

13 Para exemplificar apresenta-se o seguinte excerto retirado do sítio dedicado ao 'monumento' e que pode ser consultado em: <http://www.mm.fba.ul.pt/monumento_multiculturalidade/eventos_3sessao_copas.html>. "As três palavras-chave seleccionadas pelo grupo de Copas, com assentimento geral, foram: Diversidade étnica, Memória Rural e Rio. O Rio é a componente aglutinadora da Memória rural e da Diversidade étnica. O Rio, através da expressão da água, deve ser considerado a razão de ocupação do solo, de carácter fértil, que possibilitou o que viemos a classificar como memória rural, bem como a diversidade étnica que povoa Almada cuja população parece ter vindo de longe, por via marítima. O Rio é simultaneamente símbolo de fertilidade e de movimentos migratórios. Compreende-se neste grupo que o Monumento deve ser caracterizado essencialmente pelo conceito de Rio, como se de uma homenagem a este se tratasse, acentuando-o na paisagem, quer pela utilização do elemento água, quer pela sua forma que abraça o Monte de Caparica." 
A segunda etapa de trabalho estendeu-se por 4 sessões ${ }^{14}$ inteiramente dedicadas à concepção formal da proposta para o monumento, como se ilustra na foto 4 . Tendo como ponto de partida as palavras-chave encontradas anteriormente, os grupos de trabalho começaram a desenvolver e a construir maquetas, que mais do que uma alusão à multiculturalidade, se foram multiplicando em "pontos de encontro" e de troca que valorizam a diversidade cultural existente.

A dificuldade metodológica que se previa para esta aç̧ão prendia-se com a reacção dos participantes perante a necessidade de materializar em maquetas as ideias que foram sendo sistematicamente fixadas em palavras. Para dar início a essa construção foi montado um aparato com diferentes materiais (cartões, fitas, colas, barras de balsa, marcadores, pasta de modelar, etc.). As primeiras tentativas de materialização foram muito intuitivas e partiram dos meios mais simples e directos, como o papel, o cartão, o corte e colagem. Mas rapidamente se partiu para a complexificação das formas e para outros materiais de diferentes comportamentos plásticos e mecânicos (como a massa de modelar) ou para a tentativa empírica da representação da figura humana.

O que transparece dos resultados desta experiência - para além da adesão dos participantes - é sobretudo a riqueza que as narrativas estruturadas nas secções anteriores trouxeram à materialização plástica. Este facto deve-se ao trabalho de reapropriação colectiva das relações socioculturais com o território, que acabaria por se converter num processo de resgate da memória espacial e no fortalecimento da identidade do grupo através dessa memória.

Deste processo resultaram onze maquetas elaboradas pelos diferentes grupos, que depois de devidamente apresentadas e explicadas, como se ilustra na foto 5, foram sujeitas a processos de selecção e simplificação nas duas sessões seguintes, em que passaram a cinco maquetas.

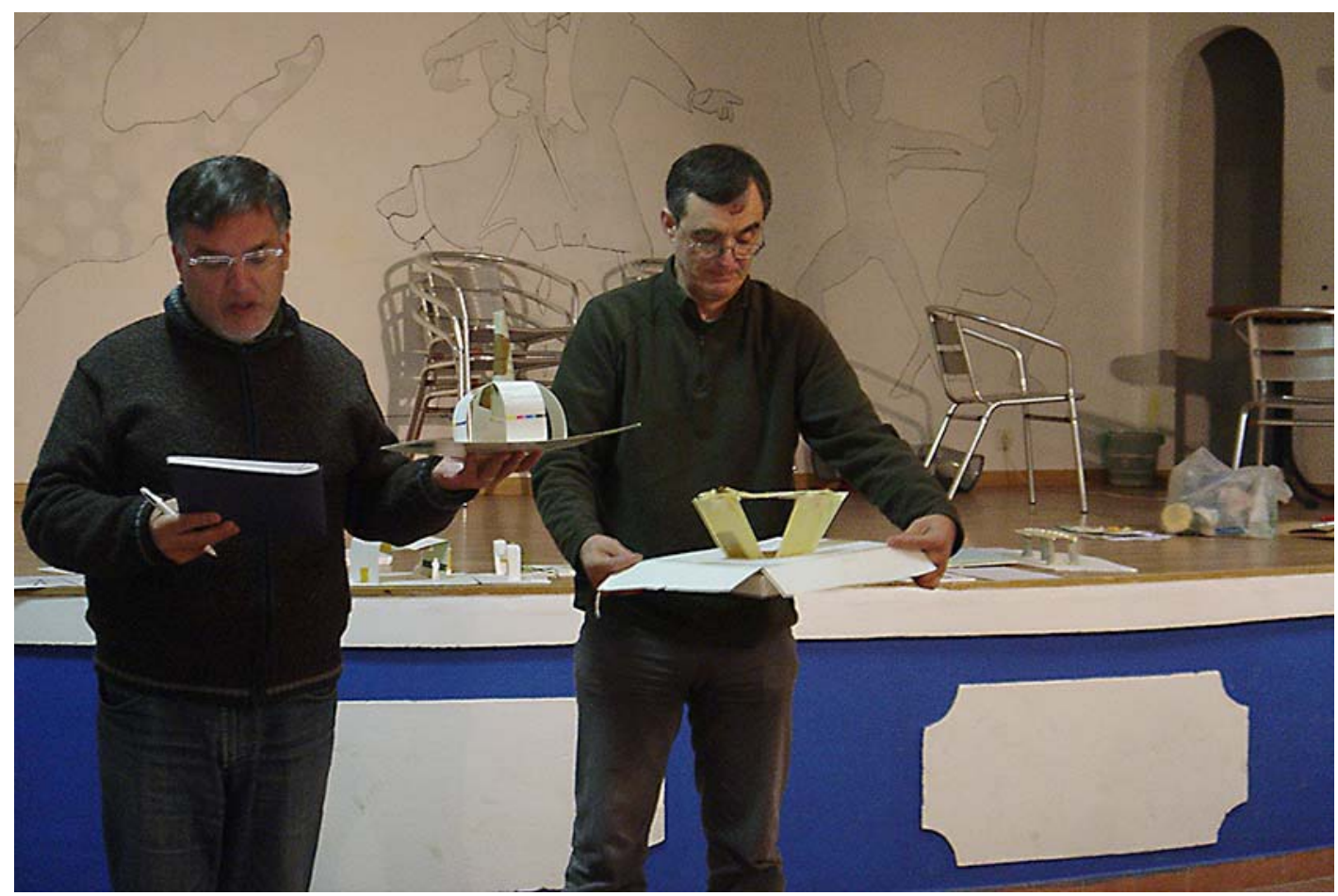

Foto 5 - Apresentação das maquetas elaboradas por um grupo aos restantes grupos presentes.

14 Realizadas respectivamente em 10/12/2011, 14/12/2011, 26/01/2012 e 2/06/2012. 
Foi sobre estas cinco maquetas que os escultores posteriormente actuaram, no sentido do nivelamento e da acentuação em termos da linguagem escultórica. Significa isto que houve a necessidade de repensar as várias propostas ao nível da escala, dos materiais, das técnicas construtivas, da qualidade das formas plásticas e da linguagem. Mas em simultâneo também houve a preocupação de intervir o menos possível nas maquetas originais.

Das cinco maquetas a equipa optou pela selecção de três, com base em critérios relacionados com a linguagem estética de conjunto e também com a valorização das ideias que estiveram na sua origem. Recusando o princípio do patchwork optou-se de forma consciente pela organização do espaço a partir dos consensos transpostos para as maquetas, com vista a que as futuras esculturas pudessem criar um discurso articulado com o território.

Depois de previamente discutida entre a Câmara Municipal de Almada e o escultor responsável, a proposta inicial de construir um "monumento" acabou por resultar na possibilidade de executar as três esculturas. No fundo esta multiplicação das peças deve-se a três factores: o empenho e a participação do grupo que se envolveu em todo o processo; a diversidade de propostas apresentadas; o interesse da entidade camarária em envolver a comunidade residente no Monte de Caparica no processo de regeneração urbana em curso através de um novo processo de criar arte pública.

Entretanto, a optimização dos recursos tecnológicos previstos para a produção das esculturas também pesou na decisão. $\mathrm{O}$ uso do aço Corten complementado com o betão à vista deixam a qualidade da matéria-prima como acabamento, reduzindo ao máximo os artifícios da simbolização da matéria, uma vez que nas conversas com os participantes a escolha dos materiais a utilizar nunca foi questão relevante.

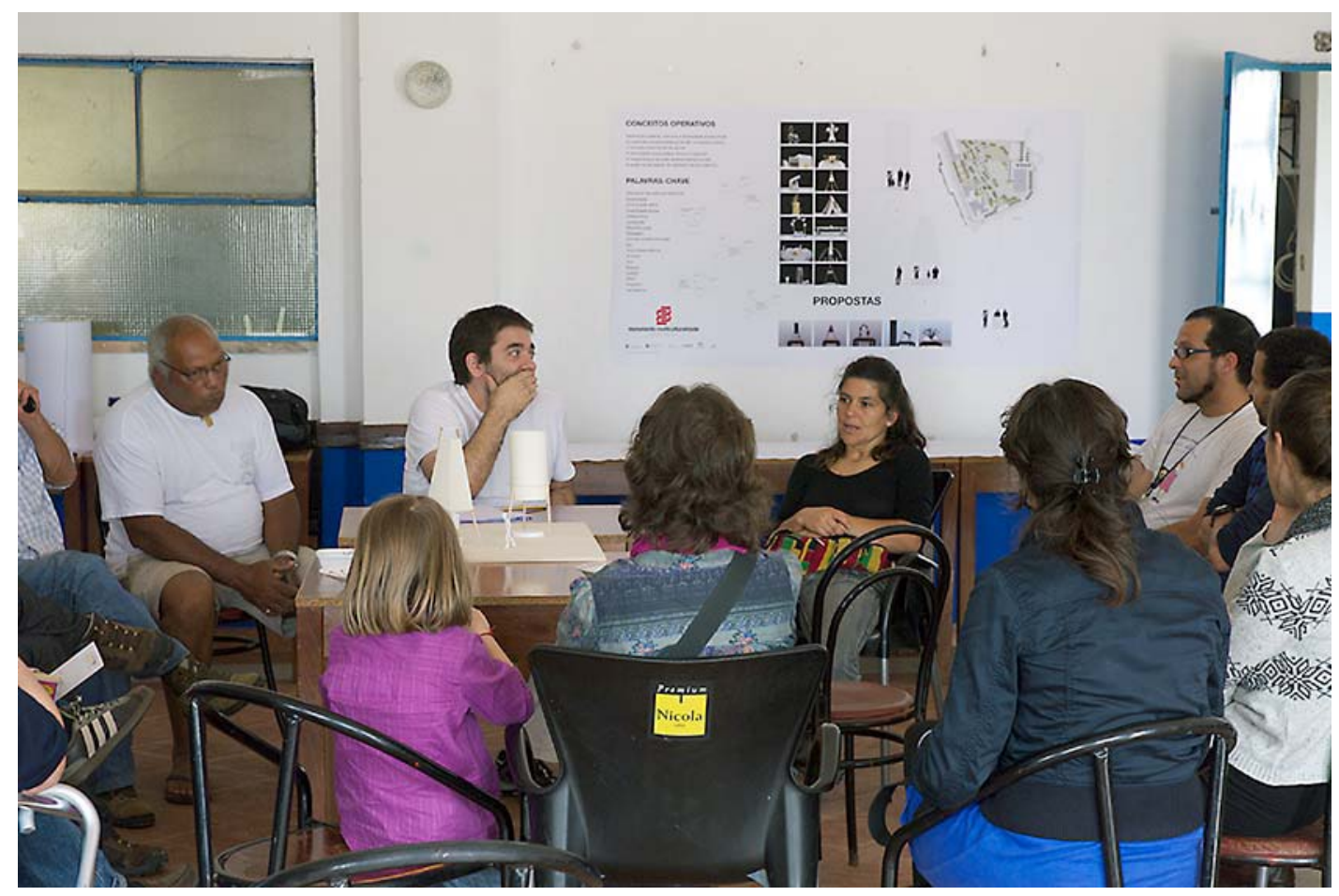

Foto 6 - Sessão de apresentação e discussão das propostas finais para as esculturas. 
Para concluirimporta referir que a última sessão de trabalho (foto 6) consistiu na apresentação e discussão colectiva das três esculturas, às quais os participantes ainda acrescentaram a cor e a palavra enquanto elementos de valorização plástica, simbólica e territorial, tal como se pode verificar na figura 7 .

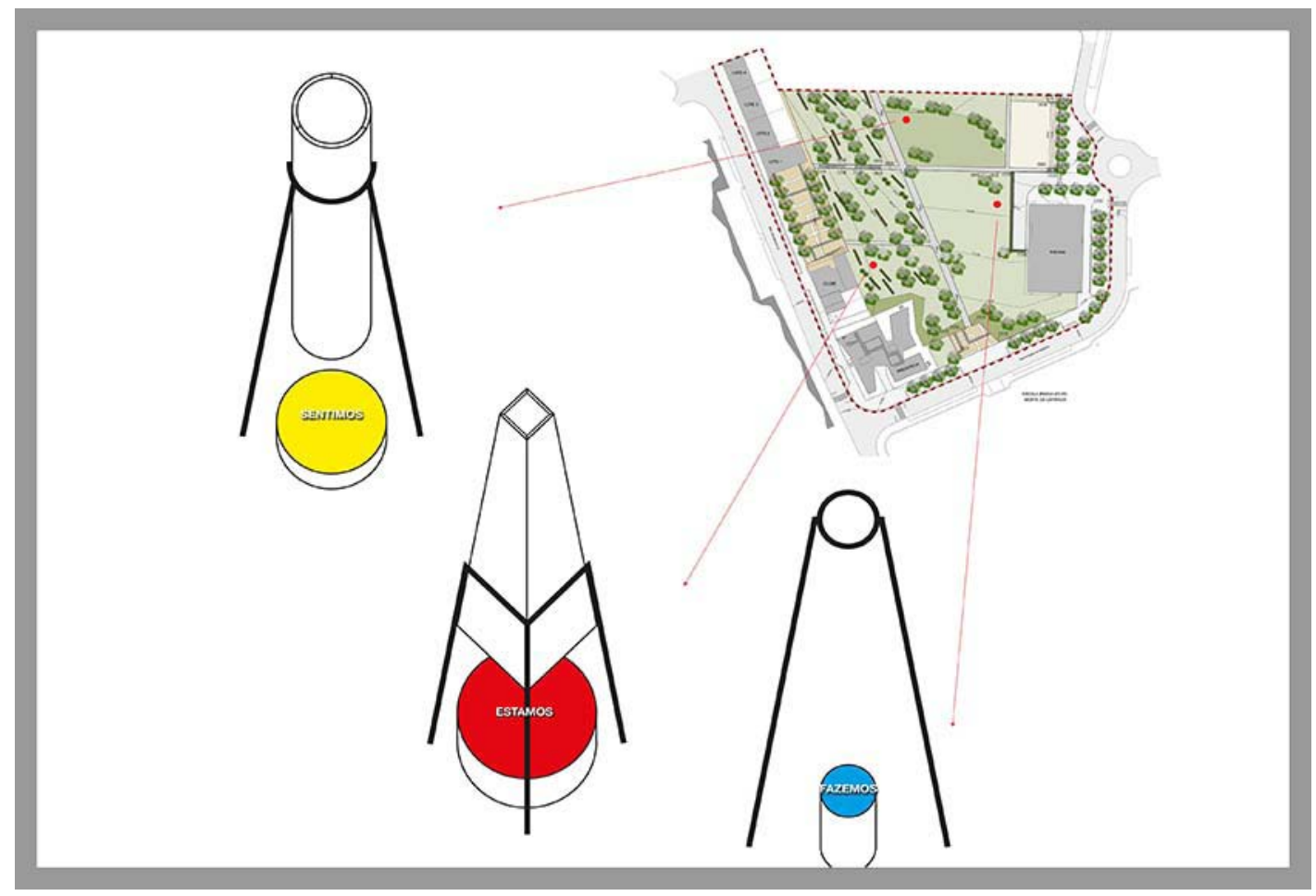

Figura 7 - Esquema das propostas e localização prevista no parque urbano.

O vermelho, o azul e o amarelo foram as cores unanimemente associadas a cada uma das três esculturas pelas ideias que simbolizam. Quanto às palavras, "estamos", "fazemos" e "sentimos" surgiram da discussão em torno do papel da obra no território onde será inserida e da sua relação com valores que a comunidade considera serem representativos da sua totalidade.

\section{Agencialidade na arte Pública participada - UMA Relação complementar?}

Depois de descrita a concepção e produção de três objectos de arte pública através de um processo participado, interessa agora retomar o debate com as conceptualizações de Gell (1998), sublinhando não só o protagonismo que os membros da comunidade assumiram enquanto agentes activos e primários ao longo das diferentes sessões de trabalho, como também a agencialidade secundária das três esculturas surgidas.

Apesar da instalação das esculturas (foto 8) no terreno estar prevista para o mês de Abril de 2013 - e da agencialidade plena das mesmas só poder ser devidamente avaliada posteriormente - é plausível o seu entendimento enquanto testemunhos materiais, que têm a particularidade de estar inseridos num contexto relacional em que os "agentes" também são "pacientes". Ainda que o universo dos "pacientes" visados por estas obras de arte vá muito para além do grupo de 
residentes que participou em todo este processo, é inteligível a leitura das esculturas enquanto "índices" da agencialidade social deste grupo.

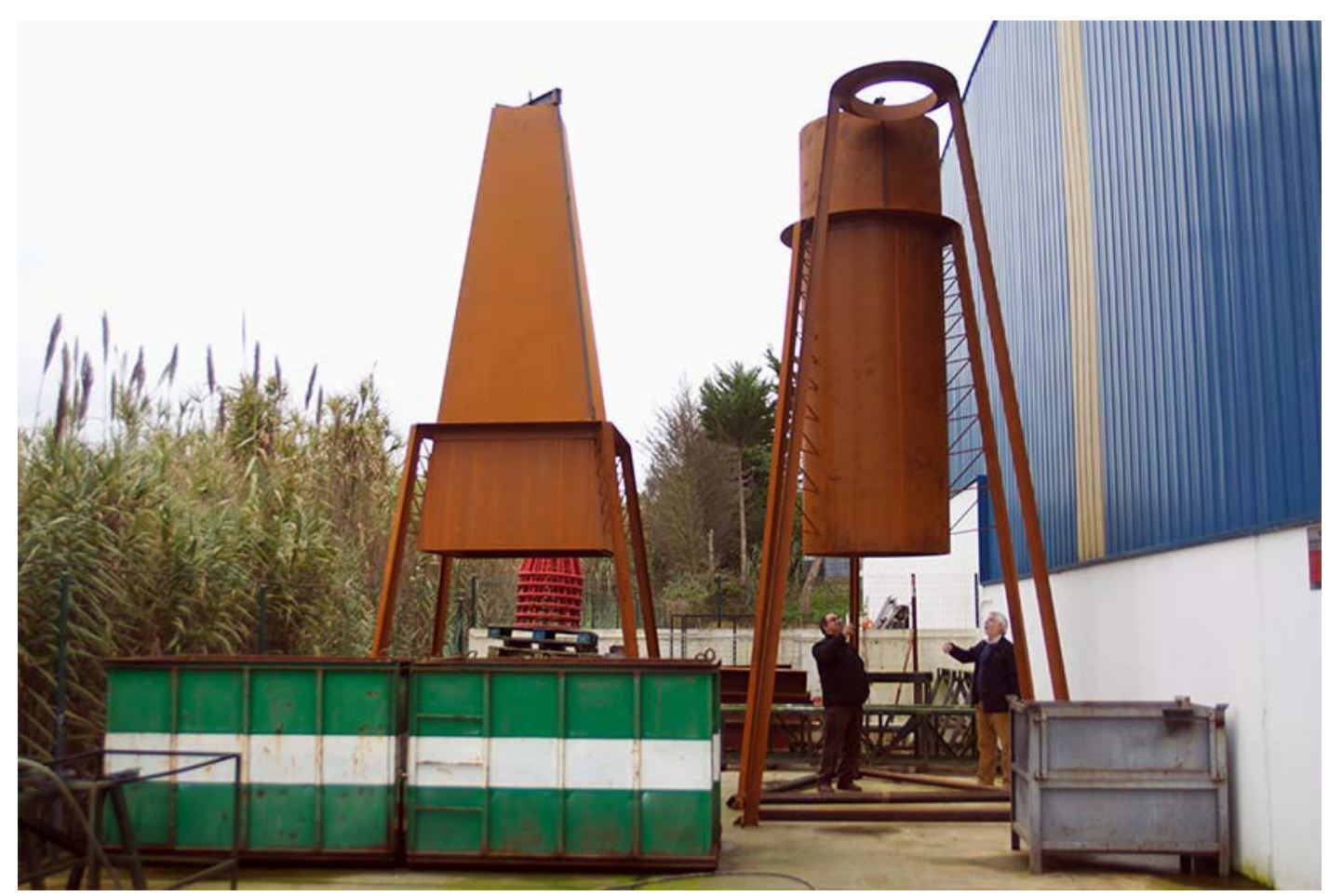

Foto 8 - Produção das esculturas em fábrica, para serem implantadas no terreno em Abril de 2013.

Com efeito, as esculturas materializam memórias, ideias, mensagens e até mesmo vontades, que vão das relações sociais e culturais intra-comunidade às apropriações e vivências que a comunidade estabelece com o seu território. Daí que para o grupo que as concebeu elas simbolizem, respectivamente: um "lugar de encontro" e diálogo entre culturas; um "lugar de reflexão" e de memórias partilhadas; um "lugar de observação" sobre a realidade envolvente. Paralelamente, também existe a expectativa, por parte da entidade camarária, de que todo o processo de envolvimento comunitário cujo produto imediato resultou nas esculturas seja mais alargado e potencie comportamentos mais envolvidos com os processos de regeneração urbana em curso naquele território.

Contudo e tal como se foi percebendo ao longo de todo o processo, a materialização referida é indissociável de uma dimensão simbólica. Assim sendo, se o entendimento das obras de arte enquanto extensões da agencialidade social dos respectivos autores permite ir ao encontro de Gell, a forma como exercem e comunicam essa capacidade acaba contrariando os propósitos do autor em desvalorizar as propriedades simbólicas e estéticas presentes na arte.

Mais relevantes do que o papel dos novos agentes sociais que produziram estes objectos de arte pública serão os objectos implantados no terreno, através do conjunto de relações que poderão gerar. Mas não sendo ainda possível avançar em pleno para essa avaliação, o reconhecimento da agencialidade destes objectos artísticos até ao momento actual acaba por revelar uma espécie de paradoxo Gellsiano. Significa isto que tanto a génese destes objectos como as formas e as mensagens que pretendem veicular apresentam-se como indissociáveis de referências simbólicas que identificam "agentes" e "pacientes" num mesmo contexto relacional. 
Paralelamente, esse facto não diminuiu o interesse pessoal ou o investimento cívico que os "agentes" associaram a estes objectos, nem diminuirá a capacidade dos mesmos confirmarem a importância do seu papel enquanto agentes na promoção de encontros, trocas e interacções junto da comunidade local.

Não obstante algumas simplificações que os escultores acrescentaram à forma estética do conjunto, os objectos artísticos conseguidos remetem para as "marcas" espaciais e identitárias de quem as produziu. Neste caso elas relacionam-se sobretudo com a salvaguarda de uma memória colectiva relativa ao espaço de vida quotidiana deste grupo, acrescentando-lhe testemunhos de novas vivências e expectativas de convivência. Um exemplo é o desejo de criar, através das esculturas, vários espaços de encontro e convívio entre os diversos grupos que coexistem neste território e cujo elemento de ligação é a evocação de uma memória espacial comum a todos.

Daqui resultará um espaço que, sendo físico, é sobretudo simbólico e evocativo de uma vontade colectivamente partilhada em promover uma maior interacção social e cultural dentro da comunidade de pertença. É neste sentido que as três esculturas podem ser entendidas como agentes sociais, apesar de emergirem enquanto "mensagem" simbolicamente construída num determinado contexto espacial e cultural.

Diz Connerton (1993) que as sociedades são comunidades que se auto-interpretam e que uma das mais poderosas auto-interpretações consiste nas imagens que as sociedades criam e preservam de si próprias como sendo continuamente existentes. Este facto deriva da consciência individual do tempo ser, em grande medida, uma percepção da continuidade da sociedade ou, mais exactamente, da imagem dessa continuidade que a sociedade cria (Connerton, 1993). Contudo, um elemento indispensável a essa auto-interpretação é o espaço, uma vez que as memórias de qualquer grupo estão localizadas no interior dos seus espaços, tanto materiais como mentais.

De facto, o espaço não é simplesmente o suporte privilegiado da identidade de um grupo (Ledrut, 1980). Ele é também o produto daquilo que o grupo é e da forma como se representa. Daí que não seja de estranhar que a produção de discursos em torno de um território comum acabe por resultar numa conformidade de representações demonstrativas do sentido de pertença face ao mesmo, face às suas memórias e para além de todas as diversidades ou multiculturalidades. Significa isto que se estabelece um laço indissociável entre o sentimento de pertença a uma colectividade e o sentimento de pertença a um território (Silvano, 1997) e que esse mesmo laço se tornou perceptível e, eventualmente mais forte através dos objectos escultóricos propostos.

Este reconhecimento de que a arte também envolve a codificação de preposições simbólicas - sobre o espaço, sobre as identidades sociais e culturais, sobre o mundo em geral - demarca-se da posição de Gell, cujo propósito é desvalorizar a presença dessa dimensão na arte. Mas em paralelo, também confirma a arte enquanto sistema de acção e, consequentemente, enquanto elemento necessariamente integrado num sistema cultural. Assim, se a perspectiva da arte enquanto sistema de acção constitui um ponto inovador na teoria de Gell, o facto desse sistema de acção não estar suportado numa moldura cultural que o contextualize de uma forma mais assumida acaba por fragilizar essa perspectiva (Layton, 2003).

No fundo o que aqui se defende é que a agencialidade que Gell atribui aos objectos por via da "abdução" - ou capacidade de inferirem ideias ou acções a outros - não é isenta de simbolismos 
e remete para tal integração cultural, na medida em que a relação de causalidade que suporta a "abdução" (ou inferência) também será incontornavelmente cultural. Como diria Geertz (1993), o sentido de qualquer acção social implica não só a relação de troca recíproca entre intérprete e interpretado, mas também a participação destes três elementos num mesmo sistema cultural.

Assim e voltando ao projecto de arte pública aqui em foco, dificilmente se compreenderia a agencialidade destas esculturas se não existisse uma "mensagem" e se a mesma não estivesse devidamente integrada no sistema cultural que envolve produtores e receptores. Considera-se ainda que o facto de as esculturas terem surgido através de um processo participado contribuirá para ampliar a agencialidade das mesmas.

No âmbito do vasto domínio que é a Cultura e sobretudo noutros países que não Portugal, o desenvolvimento de processos criativos em torno da arte pública tem vindo a revelar grandes potencialidades, quer em processos de qualificação do espaço público, quer em processos participativos. Com efeito trata-se de processos que passando pela prática do exercício de cidadania promovem o diálogo, a coesão social e a capacitação de comunidades com características semelhantes às que residem no Monte de Caparica.

Neste campo de acção a noção de arte pública carece de um reposicionamento crítico, na medida em que não se trata de um género artístico nem de uma tendência da história ou da crítica da arte. Entende-se que a arte pública se rege por critérios específicos de avaliação que integram um pensamento mais amplo centrado no espaço público. Significa isto que a percepção sobre a arte deve estar associada a outras perspectivas de análise e investigação sobre a cidade e seus espaços. Só deste modo será possível descentrar a análise da obra das suas especificidades estéticas, estilísticas ou autorais e trazê-la para um campo mais vasto de interpretações e, simultaneamente, reconhecer que o objecto artístico, quando implantado no solo da cidade, passa a ser propriedade cultural daqueles que a habitam.

Desta forma, o entendimento sobre a noção de arte pública não se pode esgotar na simplificação da arte concebida para espaços públicos e que, frequentemente, se baseia em soluções propostas pelas elites - artísticas ou políticas - destinadas à contemplação passiva das massas. Partilhando a perspectiva de Remesar (2003), a arte pública tem por objectivo o controle dos cidadãos sobre a estética do seu próprio ambiente. Como tal, a arte pública constitui-se num importante processo político de cidadania, na medida em que é a cidade em si mesma - e não os agentes mediadores pertencentes às redes culturais - quem define estilos artísticos e acede à definição de processos e fluxos de estetização do ambiente que, através de uma reflexão compartilhada, exerce controlo sobre a sua forma urbana (Remesar, 2003).

$\mathrm{Na}$ continuidade desta leitura entende Remesar que se abrem novas perspectivas ao artista enquanto facilitador social, na medida em que pode ajudar a gerar "novos discursos urbanos" que conduzam a um empowerment ou capacitação dos habitantes da cidade. Para tal, os processos de trabalho neste âmbito devem reger-se por uma perspectiva inclusiva, criando as oportunidades necessárias para que tanto a arte pública como o espaço público sejam realmente para todos (Remesar, 2003).

Desta forma, as intervenções de arte pública participada que efectivamente envolvem a participação dos cidadãos em todo o processo tendem a afirmar-se como métodos orientadores de boas práticas de cidadania, contribuindo para uma maior intervenção dos cidadãos nos seus 
territórios. Geralmente os cidadãos são coordenados por um artista plástico, que se compromete a perceber as características físicas e funcionais do espaço onde se vai intervir, bem como as inquietudes, conflitos e anseios das comunidades, de forma a oferecer-lhes respostas eficazes e culturalmente representativas (Aguilera, 2004). Mas antes de chegar a essas respostas existe todo um trabalho de parceria e co-criação entre todas as partes intervenientes no processo, de forma a garantir não só a horizontalidade na partilha e debate de ideias, mas também a identificação da comunidade com o resultado produzido e, num outro patamar de importância, o interconhecimento comunitário e a identificação e apropriação colectiva do espaço.

Sustenta ainda Ricart ${ }^{15}$ (2009) que o sucesso de um projecto de participação pública está dependente da forma como se introduzem os objectivos do projecto. Este deve estar orientado para a detecção de problemas resolúveis, deve incidir directamente na melhoria da envolvente construída e revalorizar a imagem do território, especialmente através do resgate da sua memória.

Entretanto, a metodologia empregue no projecto que se vem descrevendo também permite acrescentar a estes factores a necessidade do trabalho oficinal ser realizado por grupos de cidadãos voluntários, que se implemente o trabalho de equipa numa perspectiva interdisciplinar (trazer ao grupo a experiência de outras áreas de saber em complemento às disciplinas tradicionais do desenho) e que o trabalho seja desenvolvido a partir da experiência empírica com o território.

Face a estes postulados em torno de um certo modo de entender e fazer arte pública torna-se inteligível não só a relação de complementaridade entre a Antropologia e a Arte, mas sobretudo, a capacidade que a Arte tem de se afirmar enquanto sistema de acção e intervenção social, devidamente equilibrado em termos de categorizações estéticas, estilísticas e simbólicas.

\section{Notas finaIS}

No projecto que se desenvolveu no Monte de Caparica houve um reconhecimento e uma valorização das competências sociais e culturais de uma comunidade para se manifestar no seu território através da arte. Dessa manifestação resultaram três esculturas, que já tendo gerado algumas interacções sociais entre um grupo relativamente pequeno de intervenientes, poderão ampliar a sua capacidade de acção depois de instaladas no terreno. Desta forma se confirmará a complementaridade do processo de participação pública na agencialidade dos objectos de arte, sem desvalorizar as componentes simbólicas, estéticas e comunicacionais que sempre integraram os mesmos.

Face ao exposto importará reconhecer que o quadro conceptual proposto por Gell em torno da agencialidade presente na arte fornece ferramentas fundamentais para perceber os contextos relacionais que se estabelecem entre as comunidades e a sua cultura material e artística. Aqui se inclui não só a capacidade que os sujeitos têm de se projectar, significar e agir através dos seus objectos, mas também o protagonismo interventivo que os objectos podem assumir na vida dos sujeitos. Entretanto, também se considera que a participação directa dos sujeitos na concepção

15 Núria Ricart, escultora que esteve envolvida no projecto "Cartografias de La Mina", desenvolvido pelo CRPolis, que se desenrolou entre os anos de 2002 e 2006. Foi projecto de confluência entre arte e espaço público, com uma forte aposta em processos de participação cidadã no bairro de La Mina, em Sant Adrià de Besós (Barcelona). 
dos objectos artísticos é uma forma de complementar e até de ampliar a agencialidade de todos os elementos envolvidos nesta teia de relações, que teve no território o seu ponto de partida e de chegada.

É certo que a avaliação da agencialidade plena das esculturas requer a passagem de algum tempo sobre a respectiva implantação no território. Contudo e no imediato, já é possível avaliar a positividade de alguns efeitos junto do grupo que participou neste processo artístico, nomeadamente, nas trocas de conhecimentos, na cooperação e na partilha de experiências visando a concretização de um objectivo comum materializado nas esculturas.

Também se confirmou que a arte, sendo uma dimensão cultural por excelência, tem um papel incontornável nas dinâmicas sociais que pode potenciar. O "monumento à multiculturalidade" é um exemplo inicial, estando já em desenvolvimento outro projecto neste mesmo território, "Planisfério da Interculturalidade", envolvendo a totalidade da comunidade escolar. Em traços muito breves, trata-se de um processo que visa a participação de cada elemento dessa comunidade - cerca de 2 mil crianças - num mural colectivo, onde se farão representar através da impressão em baixo relevo de um pequeno objecto pessoal que, de alguma forma, seja significativo para a sua identidade individual e colectiva.

\section{Bibliografia}

Águas, Sofia. 2012. "Do Design ao Co-Design: uma oportunidade de design participativo na transformação do espaço público". On the W@terfront, n²2: 57-70.

Aguilera, Fernando G. 2004. "Arte, Ciudadanía y Espacio Público". On the W@terfront, n5: 36-51.

Almada, Câmara Municipal. 2008. Almada Poente: regeneração para uma nova centralidade Parcerias para a regeneração urbana, bairros críticos, Polis XXI. Almada: Câmara Municipal de Almada.

Appadurai, Arjun. 1986. The Social Life of Things: Commodities in cultural perspective. Cambridge: Cambridge University Press.

Baudrillard, Jean. 1973. O Sistema dos Objectos. São Paulo: Perspectiva.

Connerton, Paul. 1993. Como as Sociedades Recordam. Oeiras: Celta.

Costa, Ana. 2005. Da Construção Artificial aos Artifícios da Apropriação: do bairro à cidade, espaço e cultura. Lisboa: Faculdade de Ciências Sociais e Humanas da Universidade Nova de Lisboa (Tese de Mestrado).

Costa, Ana. 2006. "O Espaço dos Outros: representações sociais e fronteiras num bairro do Plano Integrado de Almada". Revista da Faculdade de Ciências Sociais e Humanas, no18: 37-57.

Geertz, Cliford. 1993. The Interpretation of Cultures. London: Fontana Press.

Gell, Alfred. 1998. Art and Agency: An Anthropological Theory. Oxford: Oxford University Press. Giddens, Anthony. 2000. Dualidade da Estrutura: Agência e Estrutura. Oeiras: Celta.

Layton, Robert. 2003. "Art and Agency: a reassessment". Royal Anthropological Institute: n99. 447-464.

Ledrut, Raymond. 1980. "Espace et Sociétés". Espaces et Sociétés, no 34-35: 3-12.

Lury, Celia. 1997. Consummer Culture. Cambridge: Polity Press.

Miller, Daniel. 1987. Material Culture and Mass Consumption. Oxford: Basil Blackwell. 
Remesar, Antoni. 2003. "Arte e Espaço Público. Singularidades e Incapacidades da Linguagem escultórica para o Projecto Urbano". Pp. 26-40 in Design de Espaço Público: Deslocação e Proximidade, P. Brandão e A. Remesar (org.). Lisboa: Centro Português de Design.

Remesar, Antoni. 2005. Arte Contra el Pueblo: los retos del arte público en el s. XXI-TXT Public Arte Observatory Project. Obtido Fevereiro 28, 2013 (http://ub.academia.edu/AntoniRemesar/ Papers/443843/Arte_contra_el_pueblo_los_retos_de 1_arte_publico_en_el_s.XXI)

Remesar, Antoni., Tomeu Vidal. 2003. Metodologias Creativas Para la Participación documento de trabajo (doctorado Espacio público y Espacio Urbano: arte y sociedad). Barcelona: Universidad de Barcelona.

Ricart, Núria. 2009. Cartografies de La Mina: Art, Espai Públic, Participació Ciutadana (PhD thesis). Barcelona: Universitat de Barcelona.

Silvano, Filomena. 1997. Territórios da Identidade. Oeiras: Celta.

Thomas, Nicolas. 2001. "Introduction" In Beyond Aesthetics: Art and the Technologies of Enchantement, C. Pinney and N. Thomas (org.). Oxford: Berg.

\section{"Today we are the sculptors!" Agency and participatory public art in Almada}

This article reflects upon a participatory public art project, based on a critical reading of Gell's theories about art as a system of action and the agency of artistic objects. The project was based on a concept of public art, actively engaging a group of residents of Monte de Caparica (close to Lisbon, Portugal), who were also intended to be the artworks' public. Based on an ethnographic account of the project and some of Gell's proposals, we defend that the role artistic objects play within a certain social environment is inseparable from their symbolic, aesthetic, representative and communicational properties. At the same time, we point to the strengthening of their capacity as agents, within the participatory perspective of the analyzed project.

Keywords: agency, public art, participation, multiculturalism. 